\title{
Microbending Experiments on Pure Magnesium with Nonbasal Slip Orientation
}

\author{
Jan Maňák * and David Vokoun \\ Institute of Physics ASCR, Na Slovance 2, CZ-182 21 Praha 8, Czech Republic; vokoun@fzu.cz \\ * Correspondence: manak@fzu.cz; Tel.: +420-266-05-2807
}

Received: 28 June 2018; Accepted: 12 August 2018; Published: 14 August 2018

\begin{abstract}
In the present study, in situ microbending experiments on magnesium single crystalline microcantilevers are presented. Microcantilevers with pentagonal cross-section were fabricated by focus ion beam. Two basic crystallographic orientations of the microcantilevers were investigated: $\{0001\}$ and $\{10-10\}$, i.e., the $c$-axis perpendicular to and parallel with the cantilever top surface, respectively. After bending, the longitudinal sections of the microcantilevers were analyzed using electron backscatter diffraction to investigate the crystal lattice rotations and accumulated deformations. The stress levels in the loaded cantilevers are strongly dependent on the crystal orientation. Extension twins were found in the $\{10-10\}$ cantilevers.
\end{abstract}

Keywords: magnesium; microcantilevers; microbending; focused ion beam (FIB)

\section{Introduction}

Magnesium is a lightweight material. Due to its low density and high strength-to-weight ratio and as well as its potential for a wide range of applications [1,2], magnesium has received a great deal of attention. One of the serious obstacles in using magnesium is its anisotropic behavior. In order to characterize the anisotropic mechanical properties, or deformation mechanisms, mechanical properties of $\mathrm{Mg}$ single crystals have been studied since the beginning of the search for lightweight materials [3-7]. During macroscopic sample preparation, some unattended and undesirable deformations may occur, which then complicate these studies of the deformation mechanisms. Recent advances in in situ mechanical tests on micrometric samples, micromachined using SEM/FIB (scanning electron microscope/focused ion beam), have yielded methods offering strong advantages over the traditional mechanical testing methods [8]. Furthermore, with emerging small-scale engineering applications, such as microelectromechanical systems and various microcomponents, the mechanical properties of magnesium at micro-scale are of interest. Since mechanical properties at micro- and macro- scale may differ due to various size-scale phenomena [9-11], further studies are necessary to determine the possibility of using miniature magnesium components for biomedical and aerospace applications $[12,13]$.

Several research groups have analyzed mechanical properties of magnesium at micro-scale, mostly working with nano- and micro-pillars [8,14-16]. To our knowledge, microbending experiments on pure single crystal magnesium have not been reported before. Most of microbending experiments were performed with fcc (face-centered cubic) or bcc (body-centered cubic) metals and alloys [17-19]. Metals with hcp (hexagonal closed-packed) crystalline structures have a reduced number of available slip systems compared to fcc and bcc metals, which make plastic deformation more difficult [20,21]. Generally, there are multiple purposes for microbending experiments and simulations with metallic materials: (i) The study of the size-effects; (ii) gaining deeper insight into microplasticity; (iii) validation of various micro-mechanical models $[10,22,23]$. 
In the present study the effect of the crystallographic orientation of $\mathrm{Mg}$ on the stress-deflection curves obtained from microbending was considered without regard for the size-effects.

\section{Materials and Methods}

Pure magnesium single crystal was produced using a Bridgman technique and oriented by XRD (X-ray Diffraction, Seifert ISO-Debyeflex 3003, XRD Eigenmann GmbH, Hormersdorf, Germany) measurements and then cut into samples with desired crystallographic orientation with the experimental error less than $1^{\circ}$. The sample went through a standard metallographic preparation followed by electro-polishing. The microcantilevers were micro-fabricated and observed using an FEI Quanta 3D Dual-Beam SEM/FIB (scanning electron microscope/focused ion beam) system (FEI, Hillsboro, USA) with a $\mathrm{Ga}^{+}$ion source operated at $30 \mathrm{keV}$ with various currents using automated milling script. In order to suppress the basal slip, the orientations of $\mathrm{Mg}$ in the microcantilevers were selected so that the basal plane was parallel or perpendicular to loading [15]. Hence the chosen orientation arrangements were favorable for the activation of nonbasal slip systems. The crystallographic orientation arrangements, denoted A, B, C, or D, of the microcantilevers, also denoted as A, B, C, or D, correspondingly, are summarized in Table 1. Maximum tensile stresses, $s_{\max }$, due to bending (see Table 1) were computed from four data sets obtained from each orientation of the microcantilevers according to formula 2 from a past study [24] ( $s=P L y / I$, where $P$ is the applied bending force, $L$ is the distance between the fixed end and the point where the force is applied, $y$ is the vertical distance between the upper surface and the neutral plane, and $I$ is the moment of inertia of the beam cross-section). Then $s_{\max }=P_{\max } L y / I$, where $P_{\max }$ is the maximum measured force. Moment $I$ depends on the geometry of the cross-sectional area of the individual microcantilevers. The in situ microbending tests were performed using a Hysitron PI 85 SEM PicoIndenter (Hysitron, Minneapolis, USA) with a cono-spherical diamond tip of $1 \mu \mathrm{m}$ diameter. The crystallographic orientations of micro-cantilever longitudinal sections were acquired using the FEI Quanta 3D equipped with an EDAX Hikari EBSD (electron backscatter diffraction) detector (EDAX, New Jersey, USA) and analyzed with a help of EDAX OIM software (version 8). Finite element analysis (FEA) was performed using Comsol Multiphysics Software (version 5.3a) [25]. Figure 1a shows one of the micro-fabricated cantilevers. Dimensions of samples A, B, C, and D defined in Figure $1 \mathrm{~b}$ and summarized in Table 2 are not far from the prescribed dimensions (length $\times$ height $\times$ depth $=22 \mu \mathrm{m} \times 4.5 \mu \mathrm{m} \times 3 \mu \mathrm{m}$ ). As for the milling procedure, an automated script with 8 -steps preparation process was made. The milling currents were ranging from $15 \mathrm{nA}$ (roughing) to $3 \mathrm{nA}$ (finishing). Figure 1c shows in situ microbending. Microcantilevers A, B, C, and D were bent with constant loading rate $50 \mathrm{~nm} / \mathrm{s}$ under displacement control mode. The simultaneous SEM observation helped maintain a precise placement of the indenter's tip. After the loading tests, it was necessary to make several cuts in order to prepare samples for the EBSD measurements. Before that, the samples were coated with a protective $W$ layer to reduce ion damage of the microcantilevers during cutting. Figure $1 \mathrm{~d}$ shows a cut-out (including the microcantilever) from the bulk sample. The cut-out was transferred and fixed to the edge of the sample with a micromanipulator. Longitudinal sections of the microcantilever were cut away. The cuts were made along the micro-cantilever axis using milling current as low as $1 \mathrm{nA}$ to minimize any damage. As for EBSD data acquisition, each sample was tilted to obtain the desired angle of tilt required for EBSD measurements. The EBSD maps were measured with a $200 \mathrm{~nm}$ step size. 
Table 1. The crystallographic orientations in samples A, B, C, and D, and maximum tensile stresses due to bending.

\begin{tabular}{ccccc}
\hline Cantilever Sample & A & B & C & D \\
\hline $\begin{array}{c}\text { Orientation (in respect to the cantilever } \\
\text { top and the cantilever axis) }\end{array}$ & $\begin{array}{c}\{0001\} \\
<10-10>\end{array}$ & $\begin{array}{c}\{0001\} \\
<11-20>\end{array}$ & $\begin{array}{c}\{10-10\} \\
<0001>\end{array}$ & $<1-210>$ \\
\hline $\begin{array}{c}\text { Visualization (cantilever top view, the } \\
\text { cantilever axis in the horizontal direction) }\end{array}$ & & & & \\
\hline $\begin{array}{c}\text { Maximum tensile stress } s_{\max } \text { at maximum } \\
\text { bending }(\mathrm{MPa})\end{array}$ & $993 \pm 194$ & $1119 \pm 178$ & $690 \pm 19$ & $663 \pm 64$ \\
\hline
\end{tabular}
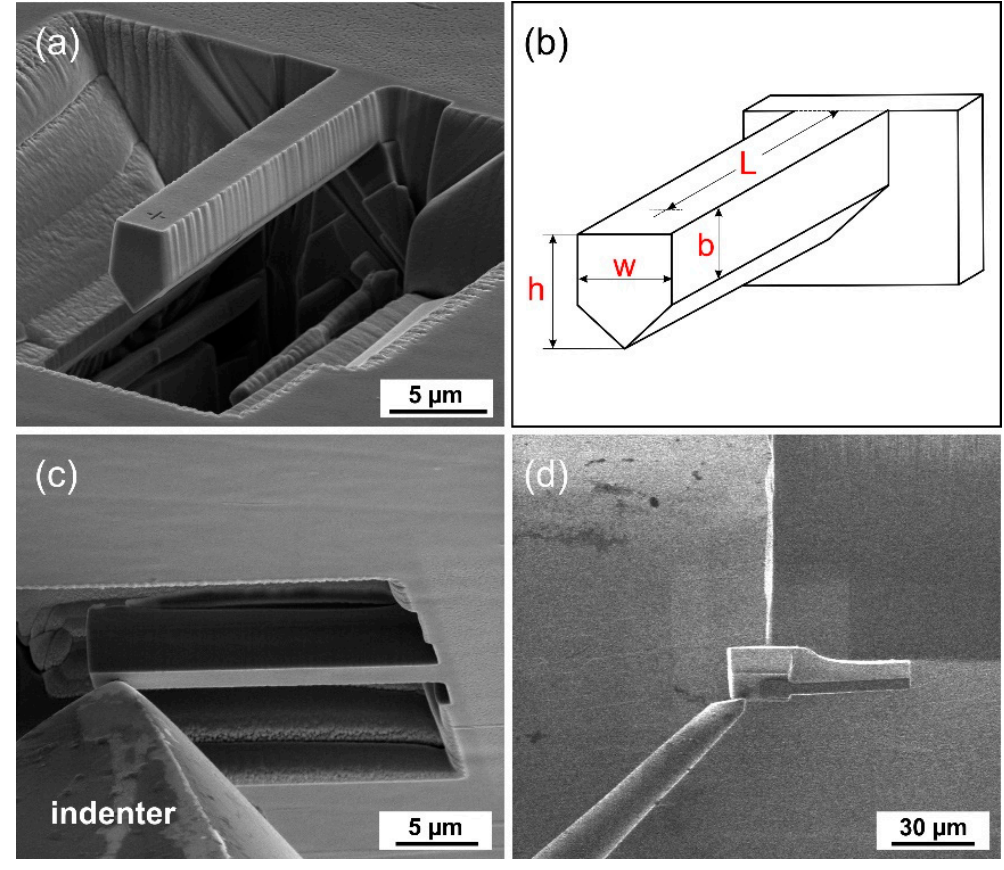

Figure 1. Microcantilever with pentagonal cross-section (a), schematic definition of geometric parameters (b) in situ microbending (c) and a cut-out of micro-cantilever (d).

Table 2. Geometric parameters of representative samples A, B, C, and D (parameters $L, w, b$, and $h$ are defined in Figure 1b).

\begin{tabular}{ccccc}
\hline Cantilever Sample & $\boldsymbol{L}(\boldsymbol{\mu m})$ & $\boldsymbol{w}(\boldsymbol{\mu m})$ & $\boldsymbol{b}(\boldsymbol{\mu \mathrm { m } )}$ & $\boldsymbol{h}(\boldsymbol{\mu \mathrm { m } )}$ \\
\hline A & 19.3 & 3.0 & 2.5 & 4.2 \\
B & 19.2 & 3.0 & 2.0 & 3.7 \\
C & 19.9 & 3.4 & 2.9 & 4.8 \\
D & 19.3 & 3.2 & 2.8 & 4.7 \\
\hline
\end{tabular}

\section{Results}

Figure 2 shows the EBSD analysis of the longitudinal sections of the cantilever samples. The results are presented by IPF (inverse pole figure) maps combined with IQ (image quality) maps. The basal plane orientations A and B show no slip or twinning mechanism in the volume. The pyramidal slip should be the favorable deformation mechanism but higher stresses are needed for its activation. The prismatic plane orientation $C$ reveals extension twin $\{10-12\}$ in the tension zone near to the fixed end. The prismatic plane orientation D exposes extension twin $\{10-12\}$ in the compression zone 
near to the fixed end. Extension twinning results in the reorientation of the original lattice of the microcantilever by an angle of $\sim 86^{\circ}$.

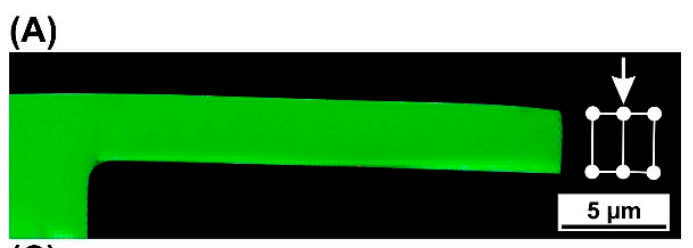

(C)

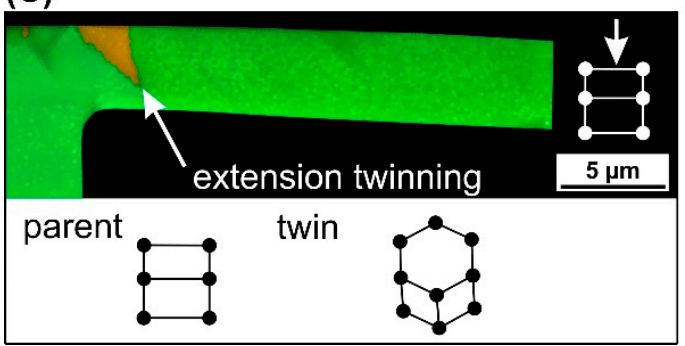

(B)

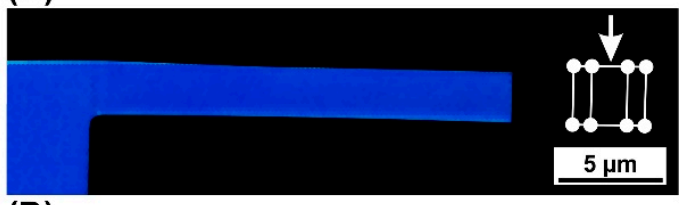

(D)

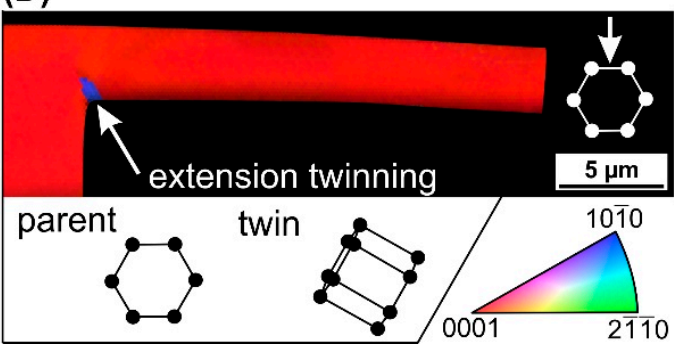

Figure 2. The electron backscatter diffraction (EBSD) analysis of the longitudinal sections of the cantilever samples. The labels (A-D) correspond to the sample crystallographic orientations (A-D). All the crystal-structure schematics are shown from lateral view of a selected microcantilever. The arrows represent the direction of the acting force.

Figure 3 shows the maximum tensile stress due to bending, $s_{z}$, versus deflection for samples A, B, $\mathrm{C}$, and $\mathrm{D}$ ( $z$ is the longitudinal axis of the microcantilever). Stress $s_{z}$ was obtained from formula 2 from a past paper [24] $(s=P L y / I)$. The curves associated with samples A and B show high stresses and no stress drop. On the contrary, the curves associated with samples $C$ and D display lower stresses and a significant stress drop suggesting ongoing twinning deformation mechanism.

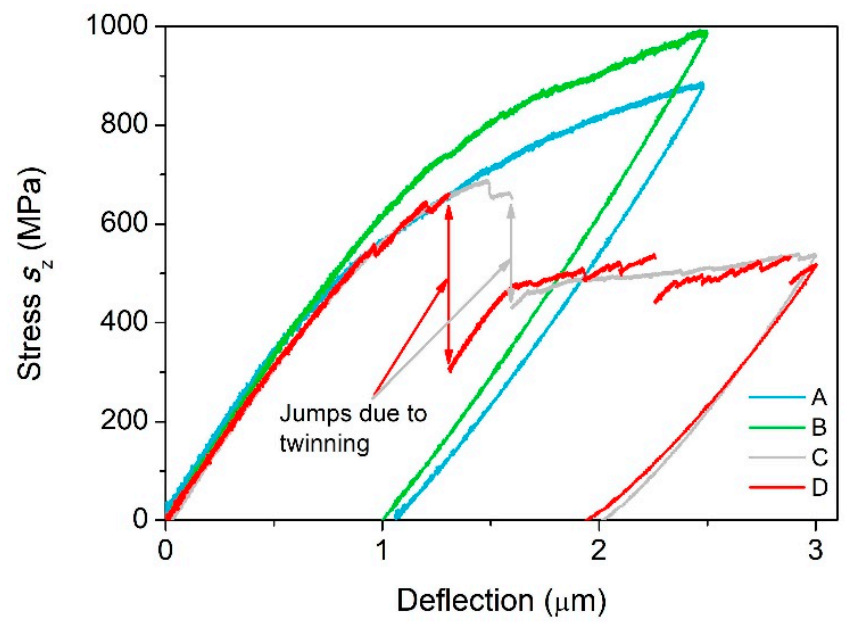

Figure 3. The diagram of stress $s_{Z}$ versus deflection for representative samples A, B, C, and D.

\section{Discussion}

Generally, the stress distribution in the bent cantilevers is of three kinds: (i) Tension stress prevails (in the tension zone), (ii) compressive stress prevails (in the compression zone of the cantilevers), and (iii) no stress component prevails (e.g., the corner area of the fixed end of the cantilever). If the other stress components in the tension and compression zones are neglected, Schmidt factors can be expressed easily for each slip/twinning system. Table 3 summarizes the largest Schmidt factors $m_{1}$ 
calculated according to a past paper [26] and the corresponding slip/twinning systems for either zone of each cantilever sample.

Table 3. The largest Schmidt factors $m_{1}$ calculated according to a past paper [26] on the condition of neglecting all the stress components except tension/compression and the corresponding slip/twinning systems for either zone of each cantilever sample.

\begin{tabular}{ccccc}
\hline Cantilever Sample & \multicolumn{2}{c}{ Tension Zone: } & Compression Zone: & Deformation Mode \\
\hline A & $m_{1}=0.433$ & $<$ a $>$ prismatic & $m_{1}=-0.5^{*}$ & extension twin \\
B & $m_{1}=0.447$ & $<\mathrm{c}+\mathrm{a}>$ pyramidal & $m_{1}=0.447$ & $<\mathrm{c}+\mathrm{a}>$ pyramidal \\
C & $m_{1}=0.5$ & extension twin & $m_{1}=0.447$ & $<\mathrm{c}+\mathrm{a}>$ pyramidal \\
D & $m_{1}=0.447$ & $<\mathrm{c}+\mathrm{a}>$ pyramidal & $m_{1}=0.447$ & $<\mathrm{c}+\mathrm{a}>$ pyramidal \\
\hline
\end{tabular}

*: In the case of compression and twinning, the lowest Schmidt factor matters.

In agreement with Table 3, extension twins were observed in the tension zone of sample C (see Figure 2) and contraction twins were observed in no sample. However, in disagreement with Table 3, no extension twin was observed in the compression zone of sample A, although extension twinning usually has the lowest critical resolved shear stress among the possible slip/twinning systems [27].

Generally, $\{10-12\}<10-1-1>$ extension twining, the most commonly occurring twinning mode in $\mathrm{Mg}$ [28], is the most favorable when a tensile stress is acting along the c-axis of Mg crystal [29]. On the other hand, $\{10-11\}<10-12>$ contraction twinning occurs only in some cases such as high strain rate when a compressive stress is acting along the c-axis of $\mathrm{Mg}$ crystal $[8,30]$. It is worth mentioning that deformation twinning is inhibited in polycrystalline $\mathrm{Mg}$ alloy samples with grain refinement less than $3 \mu \mathrm{m}$ as fine grains do not satisfy critical twinning stress before slip occurs [31]. However, such grain size does not apply to samples A, B, C, and D. The influence of grain size and other factors (including Schmidt factors) on deformation twinning is studied using statistical analyses in a past paper [32]. In the case of orientation $\mathrm{C}$, the $c$-axis of $\mathrm{Mg}$ crystal is parallel with the cantilever axis. Therefore, the extension twins form in the tension zone of the cantilever (Figure 2C). In the case of orientation $\mathrm{D}$, both tensile and compressive stresses are applied perpendicularly to the c-axis of $\mathrm{Mg}$ crystal. According to a past paper [29], forming extension twins is suppressed in the tension zone in such a case. As for forming extension twins in the corner part of the fixed end of cantilever D, their formation cannot be easily predicted because of no stress component prevails in this area, i.e., the loading is multi-axial.

Figure 2 also shows that all the longitudinal sections are bent, perhaps due to inelastic deformation (it is worth of noting that the shapes shown do not truly express inelastic deformation of the samples because of several reasons, such as the FIB cut was not precisely parallel with the cantilever axis.) The probable presence of inelastic deformation may indicate local crystal misorientations as a result of dislocation motion. Therefore, Kernel Average Misorientation (KAM) analysis was additionally carried out (the KAM images are not shown in this study). The analysis reveals that the largest misorientations (up to $2^{\circ}$ ) appear near to the fixed end, forming a narrow band (samples A and B) and at boundaries of the extension twin areas (samples $C$ and D). The observed misorientations are likely a result of dislocation motion in places of stress concentration and tightly around the extension twin areas.

Generally, bending a microcantilever results in a complex multi-axial loading. Thus, the stress distribution in the cantilever can be determined only by carrying out the FEA. Some models for plastic deformation of hexagonal metals have been developed [33,34], however these models, mostly implemented in the finite-element software Abaqus, require input parameters not available to us currently. Therefore, in this study only elastic loading is analyzed. Figure 3 indicates that deflections equal or less than $0.4 \mu \mathrm{m}$ certainly induce an elastic response of the cantilever (corresponding to maximum stress about $276 \mathrm{MPa}$ in Figure 3). Therefore, in our FEA model, the prescribed deflection was just $0.4 \mu \mathrm{m}$. Furthermore, the following elastic constants $C_{11}=58 \mathrm{GPa}, C_{12}=25 \mathrm{GPa}, C_{13}=20.8 \mathrm{GPa}$, 
$C_{33}=61.2 \mathrm{GPa}$, and $C_{55}=16.6 \mathrm{GPa}$ taken from a previous paper [35] were input into the FEA. The following value of mass density of $\mathrm{Mg}, \rho_{\mathrm{Mg}}=1738 \mathrm{~kg} / \mathrm{m}^{3}$ was used in the FEA.

Figure 4 shows the vertical mirror plane (red color) of the microcantilever. This plane was chosen for calculation of von Mises stress distribution in the individual microcantilevers (Figure 5) for deflection $0.4 \mu \mathrm{m}$. The stress distributions for microcantilevers A, B, C, and D do not differ qualitatively. The largest von Mises stress is always found at the bottom of the fixed end of the microcantilevers. The quantitative differences in the stress distribution among samples A-D are due to: (i) differences in the geometric parameters and (ii) differences in the crystal orientations. In order to see quantitative differences due to various crystal orientations among microcantilevers A, B, C, and D, elastic strain energy density in the fixed bottom corner was evaluated for the fixed cantilever dimensions $(L=20 \mu \mathrm{m}$, $w=b=3 \mu \mathrm{m}$ and $h=4.5 \mu \mathrm{m}$, which corresponds to the prescribed dimensions) and shown in Table 4 . Beside the elastic strain energy density, total elastic strain energy and the calculated \{measured\} forces corresponding to deflection $0.4 \mu \mathrm{m}$ are summarized in Table 4 . The total elastic strain energy was calculated also for the fixed cantilever dimensions $(L=20 \mu \mathrm{m}, w=b=3 \mu \mathrm{m}$ and $h=4.5 \mu \mathrm{m})$ whereas forces were calculated for the real cantilever dimensions.

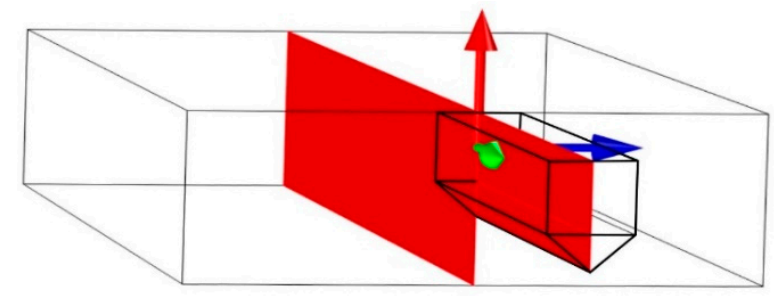

Figure 4. The vertical mirror plane (red color) of the microcantilever.

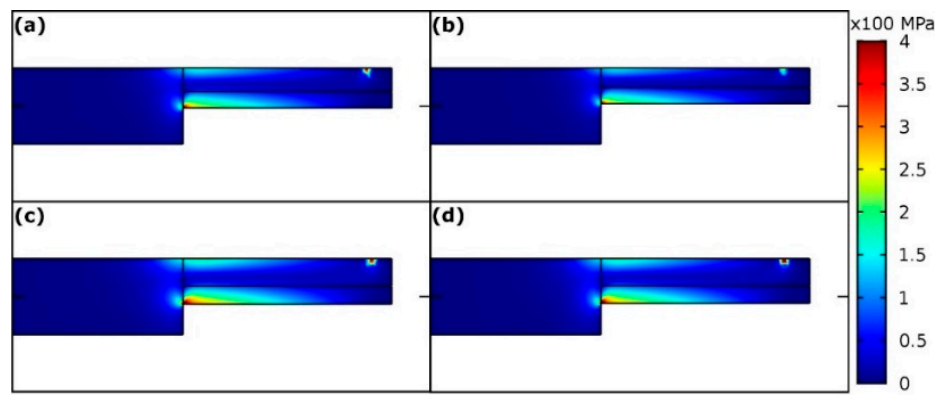

Figure 5. Von Mises stress distribution (in $\mathrm{MPa}$ ) in the vertical mirror plane of microcantilevers A-D (a-d), respectively. Cantilever deflection equals $0.4 \mu \mathrm{m}$.

Table 4. The calculated elastic strain energy density in the fixed bottom corner, calculated total elastic strain energy, and the calculated \{measured\} forces belonging microcantilevers A, B, C, and D, assuming deflection equals $0.4 \mu \mathrm{m}$.

\begin{tabular}{|c|c|c|c|c|}
\hline Microcantilever & $\mathbf{A}$ & B & $\mathrm{C}$ & D \\
\hline $\begin{array}{l}\text { Calculated elastic strain energy density at the fixed } \\
\text { bottom corner }\left[\mathrm{kJ} / \mathrm{m}^{3}\right]\end{array}$ & 9860 & 9850 & 11,700 & 12,150 \\
\hline Calculated total elastic strain energy [kJ] & 15,000 & 15,000 & 16,600 & 14,900 \\
\hline $\begin{array}{c}\text { Calculated }\{\text { measured }\} \text { forces corresponding to } \\
\text { deflection } 0.4 \mu \mathrm{m}[\mu \mathrm{N}]\end{array}$ & $62\{72\}$ & $42\{57\}$ & $104\{102\}$ & $90\{94\}$ \\
\hline
\end{tabular}

Table 4 indicates that various crystallographic orientation arrangements A, B, C, and D make difference in stress and strain distributions in respective elastically loaded microcantilevers $A, B, C$, and D. The calculated \{measured\} forces corresponding to deflection $0.4 \mu \mathrm{m}$ for cantilevers $\mathrm{A}, \mathrm{B}, \mathrm{C}$, and D were $62,42,104$, and $90 \mu \mathrm{N},\{72,57,102$, and $94 \mu \mathrm{N}\}$, respectively. A partial reason for the 
deviation between the calculated and the corresponding measured force values might be the fact that some edges of the microcantilevers were rounded. There is almost a perfect agreement between the calculated and the corresponding measured forces values in the case of samples $C$ and $D$, whereas a significant disagreement in the case of samples A and B exists. The cross-section areas of samples A and $B$ are smaller than those of samples $C$ and $D$. Therefore, mechanical properties of samples $A$ and $B$ might be influenced by Ga ion implantation during FIB more than in the case of samples C and D.

\section{Conclusions}

Pure magnesium single crystal was oriented into four various crystallographic orientations in the fabricated microcantilevers either with c-axis perpendicular to or parallel with the cantilever top surface. The stress-deflection curves were obtained from in situ microbending experiments. The basal plane orientations (A, B) showed high bending stresses and no change of crystallographic orientation in the volume. The prismatic plane orientations $(C, D)$ revealed extension twinning. The formation of extension twins in the tension zone of sample $\mathrm{C}$ and the absence of contraction twins in all the samples was in agreement with the performed Schmidt factor evaluation. The presented finite element analysis carried out for elastic loading showed (i) that the orientation arrangements make difference in strain energy densities and total strain energies, (ii) an agreement \{a disagreement\} between the calculated and the corresponding measured forces values for samples $\mathrm{C}, \mathrm{D}\{\mathrm{A}, \mathrm{B}\}$. The disagreement might be caused by a greater impact of Ga ion implantation during FIB changing mechanical properties of samples A and B.

Author Contributions: Conceptualization, J.M.; Methodology, J.M.; Formal Analysis, D.V.; Writing-Original Draft Preparation, J.M. and D.V.

Funding: This research was funded by the Grant Agency of the Czech Republic within project GA17-05360S.

Acknowledgments: The authors are thankful to L. Polívka for useful advice.

Conflicts of Interest: The authors declare no conflicts of interest.

\section{References}

1. Luo, A.A. Magnesium: Current and potential automotive applications. JOM 2002, 54, 42-48. [CrossRef]

2. Aghion, E.; Bronfin, B. Magnesium alloys development towards the 21st century. Mater. Sci. Forum 2000, 350 , 19-30. [CrossRef]

3. Burke, E.C.; Hibbard, W.R. Plastic deformation of magnesium single crystals. JOM 1952, 4, $295-303$. [CrossRef]

4. Reed-Hill, R.E.; Robertson, W.D. The crystallographic characteristics of fracture in magnesium single crystals. Acta Metall. Mater. 1957, 5, 728-737. [CrossRef]

5. Reed-Hill, R.E.; Robertson, W.D. Deformation of magnesium single crystals by nonbasal slip. JOM 1957, 9 , 496-502. [CrossRef]

6. Yoshinaga, H.; Horiuchi, R. Deformation mechanisms in magnesium single crystals compressed in the direction parallel to hexagonal axis. J. Jpn. Inst. Met. 1963, 4, 1-8. [CrossRef]

7. Kitahara, T.; Ando, S.; Tsushida, M.; Kitahara, H.; Tonda, H. Deformation behavior of magnesium single crystals in c-axis compression. Key Eng. Mater. 2007, 345, 129-132. [CrossRef]

8. Kim, G.S. Small Volume Investigation of Slip and Twinning in Magnesium Single Crystals. Ph.D. Thesis, Universite de Grenoble, Grenoble, France, April 2011.

9. Husser, E.; Bargmann, S. The role of geometrically necessary dislocations in cantilever beam bending experiments of single crystals. Materials 2017, 10, 289. [CrossRef] [PubMed]

10. Demir, E.; Roters, F.; Raabe, D. Bending of single crystal microcantilever beams of cube orientation: Finite element model and experiments. J. Mech. Phys. Solids 2010, 58, 1599-1612. [CrossRef]

11. Greer, J.R.; De Hosson, J.T.M. Plasticity in small-sized metallic systems: Intrinsic versus extrinsic size effect. Prog. Mater. Sci. 2011, 56, 654-724. [CrossRef]

12. Chen, Y.; Xu, Z.; Smith, C.; Sankar, J. Recent advances on the development of magnesium alloys for biodegradable implants. Acta Biomater. 2014, 10, 4561-4573. [CrossRef] [PubMed] 
13. Lamberson, L.E. Fatigue and Fracture of thin Metallic Foils with Aerospace Applications. Ph.D. Thesis, Georgia Institute of Technology, Atlanta, GA, USA, May 2006.

14. Liu, Y.; Li, N.; Arul Kumar, M.; Pathak, S.; Wang, J.; McCabe, R.J.; Mara, N.A.; Tomé, C.N. Experimentally quantifying critical stresses associated with basal slip and twinning in magnesium using micropillars. Acta Metall. Mater. 2017, 135, 411-421. [CrossRef]

15. Husser, E.; Lilleodden, E.; Bargmann, S. Computational modeling of intrinsically induced strain gradients during compression of c-axis-oriented magnesium single crystal. Acta Metall. Mater. 2014, 71, 206-219. [CrossRef]

16. Bočan, J.; Maňák, J.; Jäger, A. Nanomechanical analysis of AZ31 magnesium alloy and pure magnesium correlated with crystallographic orientation. Mater. Sci. Eng. A Struct. 2015, 644, 121-128. [CrossRef]

17. Ast, J.; Przybilla, T.; Maier, V.; Durst, K.; Göken, M. Microcantilever bending experiments in NiAl-Evaluation, size effects, and crack tip plasticity. J. Mater. Res. 2014, 29, 2129-2140. [CrossRef]

18. Demir, E.; Raabe, D.; Roters, F. The mechanical size effect as a mean-field breakdown phenomenon: Example of microscale single crystal beam bending. Acta Metall. Mater. 2010, 58, 1876-1886. [CrossRef]

19. Wobrock, M. Microplasticity of Idealized Single Crystalline Ag Cantilevers Characterized with Methods of High Resolution; KIT Scientific Publishing: Deutschland, Germany, 2017; Volume 68.

20. Graff, S.; Brocks, W.; Steglich, D. Yielding of magnesium: From single crystal to polycrystalline aggregates. Int. J. Plast. 2007, 23, 1957-1978. [CrossRef]

21. Lu, L.; Liu, T.; Chen, Y.; Wang, Z. Deformation and fracture behavior of hot extruded Mg alloys AZ31. Mater. Charact. 2012, 67, 93-100. [CrossRef]

22. Gupta, S.; Ma, A.; Hartmaier, A. Investigating the influence of crystal orientation on bending size effect of single crystal beams. Comput. Mater. Sci. 2015, 101, 201-210. [CrossRef]

23. Gurtin, M.E. On the plasticity of single crystals: Free energy, microforces, plastic-strain gradients. J. Mech. Phys. Solids 2000, 48, 989-1036. [CrossRef]

24. Di Maio, D.; Roberts, S.G. Measuring fracture toughness of coatings using focused-ion-beam-machined microbeams. J. Mater. Res. 2005, 20, 299-302. [CrossRef]

25. Zimmerman, W.B.J. Multiphysics Modelling with Finite Element Methods; World Scientific Publishing Co.: Hackensack, NJ, USA, 2006.

26. Nan, X.; Wang, H.; Zhang, L.; Li, J.; Jiang, Q. Calculation of Schmid factors in magnesium: Analysis of deformation behaviors. Scripta Mater. 2012, 67, 443-446. [CrossRef]

27. Barnett, M.R.; Keshavarz, Z.; Ma, X. A semianalytical Sachs model for the flow stress of a magnesium alloy. Metall. Mater. Trans. A 2006, 37, 2283-2293. [CrossRef]

28. Knezevic, M.; Levinson, A.; Harris, R.; Mishra, R.K.; Doherty, R.D.; Kalidindi, S.R. Deformation twinning in AZ31: Influence on strain hardening and texture evolution. Acta Metall. Mater. 2010, 58, 6230-6242. [CrossRef]

29. McClelland, Z.; Li, B.; Horstemeyer, S.J.; Brauer, S.; Adedoyin, A.A.; Hector, L.G.; Horstemeyer, M.F. Geometrically necessary twins in bending of a magnesium alloy. Mater. Sci. Eng. A-Struct. 2015, 645, 298-305. [CrossRef]

30. Barnett, M.R. Twinning and the ductility of magnesium alloys: Part II. "Contraction" twins. Mater. Sci. Eng. A 2007, 464, 8-16. [CrossRef]

31. Yang, Q.; Ghosh, A.K. Deformation behavior of ultrafine-grain (UFG) AZ31B Mg alloy at room temperature. Acta Metall. Mater. 2006, 54, 5159-5170. [CrossRef]

32. Beyerlein, I.J.; Capolungo, L.; Marshall, P.E.; McCabe, R.J.; Tomé, C.N. Statistical analyses of deformation twinning in magnesium. Philos. Mag. 2010, 90, 2161-2190. [CrossRef]

33. Wang, H.; Wu, P.D.; Wang, J.; Tomé, C.N. A crystal plasticity model for hexagonal close packed (HCP) crystals including twinning and de-twinning mechanisms. Int. J. Plast. 2013, 49, 36-52. [CrossRef]

34. Staroselsky, A.; Anand, L. A constitutive model for hcp materials deforming by slip and twinning: Application to magnesium alloy AZ31B. Int. J. Plast. 2003, 19, 1843-1864. [CrossRef]

35. Simmons, G.; Wang, H. Single Crystal Elastic Constants and Calculated Aggregate Properties; The MIT Press: Cambridge, MA, USA, 1971.

(C) 2018 by the authors. Licensee MDPI, Basel, Switzerland. This article is an open access article distributed under the terms and conditions of the Creative Commons Attribution (CC BY) license (http:/ / creativecommons.org/licenses/by/4.0/). 